\title{
Book Review Interdisciplinarity and Wellbeing
}

\section{Claire Duddy}

Nuffield Department of Primary Care Health Sciences, University of Oxford, Oxford, UK

Radcliffe Observatory Quarter,

Woodstock Road,

Oxford OX2 6GG.

$+44(0) 1865289300$

claire.duddy@phc.ox.ac.uk

https://orcid.org/0000-0002-7083-6589

Claire Duddy is funded by a National Institute of Health Research (NIHR) Research Methods Programme Systematic Review Fellowship (NIHR-RM-SR-2017-08-018) 


\section{Book Review Interdisciplinarity and Wellbeing}

Interdisciplinarity and Wellbeing adds the critical realist voice to the chorus of those convinced of the need for research and practice that transcends disciplinary boundaries. The authors present a convincing realist argument for the necessity of such work, in order that it account for the multiple mechanisms or structures at work in a layered reality, and present holistic theories of causation. For critical realists, the framework outlined here provides a hopeful image of the future of interdisciplinary work, in which common purpose and metatheoretical understanding ensure that individual specialisms find their place within a coherent whole. The authors paint a picture of research and practice where cross-disciplinary understanding can flourish and individual specialisms are 'enhanced' and 'integrated as a coherent totality, which is more than the sum of its parts'.

Belief in the importance of interdisciplinarity in research, practice and policymaking is by now so well-established that it has come almost to be taken for granted. The need for research that crosses traditional disciplinary boundaries is seen as particularly important for some of the biggest and most important issues facing humanity; as a recent Nature (2015) feature termed them, the "grand challenges of energy, food, water, climate and health”. Recognition of the crucial role of interdisciplinary work (and the limitations of work constrained within any single discipline) is, as the authors of this book note, reflected in the policies and public pronouncements of research institutions and their funders (see, e.g., Callard and Fitzgerald 2015, HEFCE 2017, MRC 2018).

However, defining interdisciplinarity is not straightforward and the espoused recognition of the need for interdisciplinarity in health sits uneasily alongside the familiar hierarchies of research methods of 'evidence based medicine’. 
Interdisciplinarity and Wellbeing exposes this gulf clearly, highlighting the established 'methodological imperialism' that places 'hard', quantitative methods above 'soft' qualitative research, and its devastating consequences for interdisciplinary work. This book outlines a distinct critical realist approach with the opportunity to reconcile the two sides of this enduring divide. Using critical realism to argue for the need for interdisciplinarity allows the authors to embrace the potential contribution of each individual discipline in achieving this aim.

Berth Danermark and Leigh Price began work on this book in collaboration with Roy Bhaskar, who died in 2014 before it could be completed. Their aim is that the work will 'underlabour' for interdisciplinarity in health, and beyond. That is, they endeavour to provide a philosophical account of the necessity of interdisciplinary work and then address the question of how such interdisciplinarity can and should be practiced.

The book is structured in three parts. In part one, the authors provide a concise and useful thematic literature review of existing perspectives on interdisciplinarity. They contrast the enthusiasm for inter-, multi-, trans- and cross-disciplinary approaches of many researchers and august organisations with numerous problems in its actual practice. These barriers and failures will be familiar to many readers and especially to interdisciplinary researchers and practitioners, including, for example, apparently irreconcilable cultural clashes between individual disciplines and their individual researchers, and a lack of institutional support and infrastructure for interdisciplinary work.

For the authors, most contemporary analysis of these issues falls short of understanding the root of the problem, which they identify as 'the absence of an adequate metatheoretical perspective': the lack of a common understanding of the 'ultimate goal’ of interdisciplinary work as the 'integration of knowledge'. Having 
established the need to address this gap, the authors go on to develop a critical realist general theory of interdisciplinarity, and then provide a series of examples and recommendations to support its practice.

Part two provides both a short walk through the main ideas, arguments and tools of the critical realist approach, and then develops the 'ontological case' for interdisciplinarity. The authors use the term 'applied critical realism' here, at times as a synonym or shorthand for interdisciplinarity itself. Chapters 4 and 5 trace the development of Bhaskar's thinking and helpfully contextualise its history, from his 'initial brief' in developing a new, realist ontology that could explain experimental activity in the natural sciences, through the extension and application of his ideas for the social sciences. Chapters 6 and 7 extend these arguments to develop the case for interdisciplinarity.

This section of the book is based on a series of lectures delivered by Bhaskar himself in 2009. Danermark and Price admit in the Foreword to making considerable changes to increase accessibility, presumably in response to the oft-levelled criticism of the impenetrability of Bhaskar's work. They are often successful, making this section of the book a useful primer on critical realism for a new student. In particular, the explanation of the important concepts of immanent critique, structure and agency, and emergence are clear and coherent. The discussion of 'open' versus ‘closed' systems provides an interesting alternative perspective on the dominant methodologies in health research: from this angle, 'bias' and 'confounders' in randomised controlled trials and observational studies are the inevitable result of an inability to adequately 'close' the experimental system, so that other causal mechanisms are still in operation. Part two closes with a chapter summarising the differences between critical realist metatheory and methodology and other traditions. The emphasis here on what critical realism is not 
provides additional clarity and the contrasts drawn between critical realism and empiricism, neo-Kantianism, hermeneutics and social constructionism do help to illuminate the inclusive critical realist position.

The end goal of applied critical realism (and so for the authors, for interdisciplinarity) is the development, via retroductive reasoning, of 'transfactual', universal theories about the generative mechanisms that explain observed patterns of events. For the social and human sciences, including health and wellbeing related research, such theories must explain events in 'open systems'. Our 'open', social world is characterised by a multiplicity of causal mechanisms, all at work simultaneously. These mechanisms or structures exist and operate at different levels or 'laminations' of reality, and the result is that a multiplicity of theories and disciplines is required to develop a holistic understanding of the subject under study. As the authors put it, successful interdisciplinary collaboration relies on recognition of the 'mismatch between the [individual] disciplines and the unified objects that they study'.

A familiar parallel is drawn here with George Engel's 'biopsychosocial' approach to health and wellbeing, in contrast to the 'physicalist' model that continues to dominate in some areas (and on which common understanding of 'high quality' research methods is based). The emphasis is on avoiding reductionism, which necessarily entails ignoring the inherent 'multimechanismicity' of the open system and producing only a partial picture. In previous work on disability research, rehearsed in chapter 11, Bhaskar and Danermark argued for the need to consider seven separate 'laminations' of reality. The authors make no prescription here; the question of how many and which 'laminations' will be sufficient to produce an adequately holistic description is left open. The temptation to be avoided then in future research is that of simply adopting a framework used elsewhere, without consideration of the particular 
features of the reality under investigation (or worse still, adopting a model based simply on the availability of relevant disciplinary expertise or resources).

Figure 12.1 in chapter 12 provides a useful visualisation of the 'phases' of interdisciplinary research, illustrating the progression from the understanding provided by individual specialisms to the production of 'integrated, transitive knowledge' about the real object of investigation. There is an important step between multidisciplinarity (which risks eclecticism) towards the 'integration of knowledge' that characterises truly interdisciplinary work. This step is described by the authors in a variety of ways: for example, as ‘epistemic emergence', or a 'transdisciplinary moment'; the 'genuinely creative work between the disciplines' that results in the production of 'something qualitatively new’. This surplus element is characteristic of realist research; it is the result of applying retroductive reasoning to explain the generative mechanisms or structures that are the deep causes of what is empirically observed. This theorising step is followed by a process of eliminating alternative theories, based on the application of ‘judgemental rationality' in determining which theory is the best 'fit', providing the best explanation of the 'currently available evidence'.

The creative element is difficult to pin down. The authors describe various processes that might be involved, including use of 'past cognitive successes in other disciplines', analogy, metaphor, or new or repurposed vocabulary. They neatly summarise: 'creative scientists are a bit like cognitive magpies, picking up interesting resources... wherever they can find them in order to construct an explanation that fits with the new kind of reality they have unearthed". Not only does this statement make clear the need for interdisciplinary researchers to flit between disciplines as required, it also offers a refreshing and appealing break with traditions that emphasise the need to minimise researchers' fallibility and subjectivity. 
The process of 'judgemental rationality' is described in the book as the 'objective grounds' on which one explanatory theory is preferred over another. The authors' exposition is short and to the point: 'theory A can be judged as preferable to theory B, in virtue of its ability to explain not only those aspects of reality explained by theory B, but also some additional features'. This definition may seem too simple for our complex world: it is not clear, for example, how we would choose between a theory A that explained $n$ 'features of reality' and a theory ' $\mathrm{B}$ ' that explained some additional features but perhaps could not account for one or more of the original set. This process must be seen in the context of the inherent uncertainty that accompanies a realist ontology that holds that 'real' features of reality may never be manifest in actual events, nor experienced or measured at the level of the empirical. Resolution comes in the acknowledgement of the fallibility of such theories and an emphasis on 'transparency' in the process of judgemental rationality, as a bulwark against 'attempts to choose a theory that suits certain agendas, rather than one that best explains all the evidence’. In chapter 14, Price acknowledges potential discomfort for the researcher who uncovers an 'inconvenient truth' or theory that challenges previous assumptions. There are echoes here of the 'informed guesswork' and ‘corrigible realism' approaches espoused by Pawson (2013) in his manifesto for 'scientific realism' in evaluation science. Overall the authors' argument for the philosophical necessity of interdisciplinarity is likely to appeal to realists of all stripes.

The final section of the book opens with a short chapter providing a specific argument for the need for interdisciplinarity in health. The authors point to the placebo effect as evidence that health cannot be understood with reference to the biophysical dimension alone. They argue instead for health research to explore a 'holistic ensemble' of causal mechanisms. The following chapter provides a critical realist interpretation of what are termed the 'seven enigmas' - steps taken by health practitioners in reaching a diagnosis and providing treatment. Here the authors highlight a number of issues that will be familiar to both practitioners and researchers, including the power of 'labelling' and the danger of conflating correlation with causation. In particular, the authors emphasise the potential pitfalls of basing treatment and health policy decisions solely on empirical research that can only present statistical correlations or associations, but not 
speak to causal mechanisms. In this reading, the 'methodological imperialism' that prizes correlational statistical analysis over disconfirming facts and anomalies prevents the development of theory that could potentially account for both.

There are some aspects of the book that could prove challenging for particular audiences. At times, the wide variety of critical realist models, frameworks and terminology may be overwhelming to those not already well-versed in the approach. There is a risk here that readers unfamiliar with critical realism will be distracted from the book's overall message. Some of the examples used throughout the 'Applied' section of the book may be uncomfortable for some readers. The short step between the discussion of the placebo effect and the success of complementary medicine may frustrate some devotees. The suggestion that 'avoiding Googling the symptoms' may carry a health benefit could be read as placing blame on the individual anxious patient, as could the later emphasis on patient agency (as in for example, 'perhaps it would be better to empower ourselves by emancipating ourselves from those behaviours that lead to our weight problems'). At times, the book offers models that can only really be applied to particular conditions: it is difficult to imagine how the 'emancipatory dialectic' of 'TTTTФ praxis' described for a patient with anorexia nervosa could straightforwardly be applied to a terminal cancer diagnosis, for example. It may also have been interesting to include some discussion of alternative 'realist' approaches, given their increasing traction in health research and ongoing debates elsewhere in the literature (see, e.g. Porter 2015, Pawson, 2016, Van Belle et al 2016, Bonell et al 2016).

The authors have also given consideration to more pragmatic matters in relation to interdisciplinary practice, endorsing many 'laudable’ recommendations drawn from the existing literature, particularly in relation to improving institutional support. However, their emphasis remains with the need for 'metatheoretical unity' and for what they term 'theoretical pluralism and tolerance', or in other words, mutual respect between the disciplines. This brings us back again to the beginning, and the hierarchy of research methodologies and disciplinary traditions that persists in health research. It also raises interesting questions for another research model, that of co-production, or research produced in collaboration with patients, practitioners and 
policymakers: to what extent would these groups also need to share in this metatheoretical unity?

Interdisciplinarity and Wellness is an engaging and accessible book that presents a clear argument for interdisciplinarity, and a cogent challenge to both 'reductionism' and 'eclecticism'. Although the book focuses on health and wellbeing, it is clear that the same arguments could (and should) be applied in other research and policy areas. The authors' achievement in combining philosophical argument for interdisciplinarity with practical recommendations for research and practice in healthcare ensures its wide relevance. Not only does the book provide clear justification for working across and between disciplines, it also delivers a wide range of critical realist tools and frameworks for those adopting this approach in their research and practice.

\section{References}

Bonell, C, Warren, E, Fletcher, A and Viner, R. 2016. "Realist trials and the testing of context-mechanism-outcome configurations: a response to Van Belle et al.” Trials 17:478. doi:10.1186/s13063-016-1613-9

Callard, F and Fiztgerald D. 2015. "Why it's time to get real about interdisciplinary research.” The Guardian, 14 October. https://www.theguardian.com/science/politicalscience/2015/oct/14/why-its-time-to-get-real-about-interdisciplinary-research HEFCE (Higher Education Funding Council for England). 2017. “Interdisciplinary Research”. http://www.hefce.ac.uk/rsrch/interdisciplinary/ MRC (Medical Research Council). 2018. "Interdisciplinary Science”. https://mrc.ukri.org/successes/investing-for-impact/discovery-formedicine/interdisciplinary-science/

Pawson, R. "Informed guesswork: the realist response to complexity”. Chap 5 in The Science of Evaluation: A Realist Manifesto. London: SAGE Publications Ltd.

Pawson, R. “The ersatz realism of critical realism: A reply to Porter.” Evaluation 22 (1): 49-57. doi:10.1177/1356389015605206

Porter, S. “The uncritical realism of realist evaluation.” Evaluation 21 (1): 65-82. doi:10.1177/1356389014566134 
Van Belle, S, Wong, G, Westhorp, G, Pearson, M, Emmel, N, Manzano, A and Marchal, B. “Can 'realist' randomised controlled trials be genuinely realist?” Trials 17:313. doi:10.1186/s13063-016-1407-0

Various authors (2015) Special issue on interdisciplinarity, Nature, 16 September 2015. https://www.nature.com/news/interdisciplinarity-1.18295 